
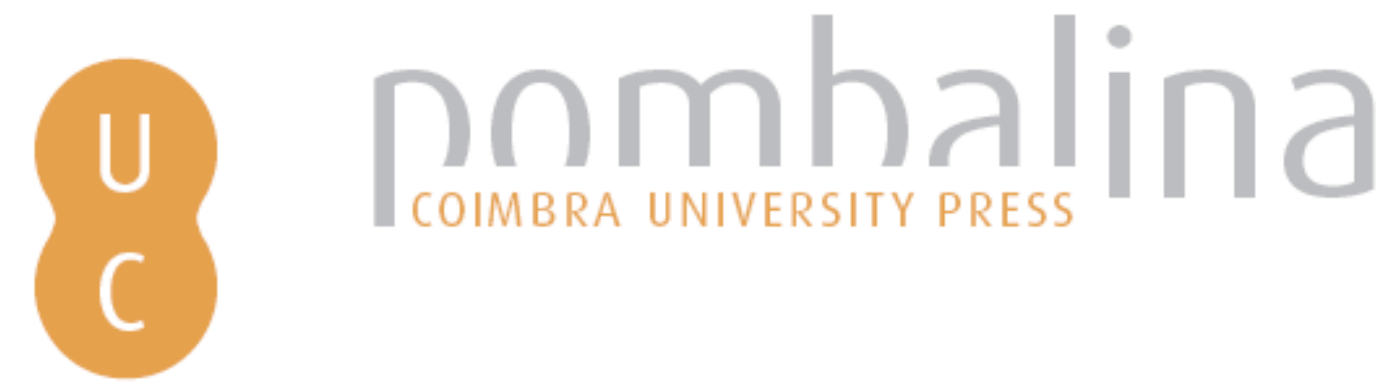

\title{
Criminalidade Feminina nas Visitas Pastorais da Diocese de Coimbra: o caso da paróquia de Pombal (16491805)
}

\author{
Autor(es): $\quad$ Oliveira, Ricardo Pessa de
}

Publicado por: Imprensa da Universidade de Coimbra

URL

persistente: URI:http://hdl.handle.net/10316.2/37190

DOI: DOl:http://dx.doi.org/10.14195/978-989-26-1033-7_3

Accessed : $\quad$ 26-Apr-2023 12:05:32

A navegação consulta e descarregamento dos títulos inseridos nas Bibliotecas Digitais UC Digitalis, UC Pombalina e UC Impactum, pressupõem a aceitação plena e sem reservas dos Termos e Condições de Uso destas Bibliotecas Digitais, disponíveis em https://digitalis.uc.pt/pt-pt/termos.

Conforme exposto nos referidos Termos e Condições de Uso, o descarregamento de títulos de acesso restrito requer uma licença válida de autorização devendo o utilizador aceder ao(s) documento(s) a partir de um endereço de IP da instituição detentora da supramencionada licença.

Ao utilizador é apenas permitido o descarregamento para uso pessoal, pelo que o emprego do(s) título(s) descarregado(s) para outro fim, designadamente comercial, carece de autorização do respetivo autor ou editor da obra.

Na medida em que todas as obras da UC Digitalis se encontram protegidas pelo Código do Direito de Autor e Direitos Conexos e demais legislação aplicável, toda a cópia, parcial ou total, deste documento, nos casos em que é legalmente admitida, deverá conter ou fazer-se acompanhar por este aviso.

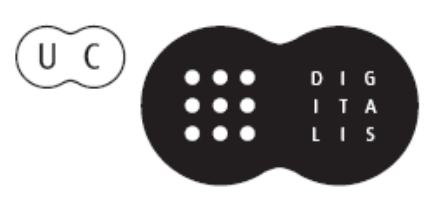


AS MULHERES PERANTE

OS TRIBUNAIS DO

ANTIGO REGIIME NA PENÍNSULA JBÉRICA

ISABEL M.R. MENDES DRUMOND BRAGA MARGARITA TORREMOCHA HERNÁNDEZ (COORDENAÇÃO)

IMPRENSA DA

UNIVERSIDADE

DE COIMBRA

COIMBRA

UNIVERSITY

PRESS 


\section{CRIMINALIDADE FEMININA NAS VISITAS PASTORAIS DA DIOCESE DE COIMBRA. O CASO DA PARÓQUiA DE POMBAL ( 1649-1805)}

Ricardo Pessa de Oliveira CIDEHUS-UE*

1. "Estabelecer a doutrina sã e orthodoxa, excluidas as heresias, manter os bons costumes, emendar os maos, com exhortações e admoestações, accender o Povo á Religião, paz e innocencia; e estabelecer o mais que o lugar, tempo e ocasião permittir para proveito dos Fieis, segundo o julgar a prudencia dos que visitarem" ${ }^{1}$. Foi desta forma que os conciliares reunidos em Trento (1545-1563), após determinarem que os prelados visitassem, ao menos a cada dois anos, a totalidade da diocese, por si, não estando legitimamente impedidos, ou por intermédio de um visitador, estabeleceram genericamente os objetivos da prática visitacional ${ }^{2}$. Pretendia revitalizar-se um mecanismo que remontava aos primórdios do Cristianismo, mas que entre finais do século XII e meados do século XVI, entrara em decadência,

* Doutor em História, especialidade de História Moderna, pela Faculdade de Letras da Universidade de Lisboa. Membro integrado do CIDEHUS-UE. Este trabalho é financiado por Fundos Nacionais através da FCT - Fundação para a Ciência e Tecnologia no âmbito do projecto UID/HIS/00057/2013.

1 O Sacrosanto, e Ecumenico Concilio de Trento em Latim e em Portuguez, tomo II, Lisboa, Oficina Patriarcal, 1781, p. 271.

${ }^{2}$ O Sacrosanto, e Ecumenico [...], tomo II, pp. 269-271. Sobre o Concílio de Trento, cf. a síntese apresentada por Adriano Prosperi, Il Concilio de Trento e la Controriforma, Trento, Edizioni U.C.T, 1999. Consulte-se ainda John W. O'Malley, Trent. What Happened at the Council, Cambridge (Massachusetts), Londres, The Belknap Press of Harvard University Press, 2013. 
facto intimamente ligado ao aumento de privilégios e isenções de distintas entidades da Igreja, em detrimento do poder episcopal ${ }^{3}$.

A visita pastoral pós-tridentina, que em Portugal assumiu contornos específicos que a distinguiram das realizadas noutros territórios europeus, especificidade que resultou do alargado poder jurisdicional que os prelados detinham sobre leigos ${ }^{4}$, além de constituir um dos principais meios da afirmação da autoridade episcopal nas respetivas dioceses, assumiu-se crucial com vista à persecução da reforma católica, nas suas diversas vertentes, nomeadamente no disciplinamento e na moralização das condutas dos fiéis.

2. No presente texto pretendemos estudar os desvios comportamentais protagonizados por mulheres delatadas em sede de visita pastoral, conferindo particular relevo às questões ligadas à sexualidade. Após traçarmos um quadro geral dos delitos cometidos por elementos do sexo feminino, importará caracterizar as denunciadas, tentando apreender em que circunstâncias cometeram as transgressões, quais os delitos que originaram processos no auditório eclesiástico e quais as sentenças decretadas por esse tribunal, tentando, por último, aferir dos impactos causados por ambos os mecanismos de disciplinamento social na existência e nos comportamentos dessas mulheres.

O espaço geográfico em análise será a paróquia de Pombal, localizada na zona sul da diocese de Coimbra, arcediagado de Penela 5 . Tratou-se

3 Sobre a visita cf. a síntese apresentada por José Pedro Paiva, "As Visitas Pastorais", História Religiosa de Portugal, direção de Carlos Moreira Azevedo, vol. 2, Humanismos e Reformas, coordenação de João Francisco Marques e António Camões Gouveia, Lisboa, Círculo de Leitores, 2000, pp. 250-255. Cf., igualmente a entrada de Joaquim Ramos de Carvalho, José Pedro Paiva, "Visitações", Dicionário de História Religiosa de Portugal, direção de Carlos Moreira Azevedo, vol. P-V, Apêndices, Lisboa, Círculo de Leitores, 2001, pp. 365-366.

${ }^{4}$ Joaquim Ramos de Carvalho, As Visitas Pastorais e a Sociedade de Antigo Regime. Notas para o Estudo de um Mecanismo de Normalização Social, Coimbra, Provas de capacidade científica apresentadas à Faculdade de Letras da Universidade de Coimbra, 1985, exemplar mimeografado; Idem, "A Jurisdição Episcopal sobre leigos em matéria de pecados públicos: As visitas pastorais e o comportamento moral das populações portuguesas de Antigo Regime", Revista Portuguesa de História, tomo XXIV, Coimbra, 1990, pp. 121-163. Sobre as provisões publicadas entre 1564 e 1578, que possibilitaram a consolidação da referida jurisdição, cf. Marcello Caetano, "Recepção e Execução dos Decretos do Concílio de Trento em Portugal", Revista da Faculdade de Direito da Universidade de Lisboa, vol. XIX, Lisboa, 1965, pp. 7-87.

5 A propósito da diocese conimbricense cf. a síntese apresentada por António de Jesus Ramos, "Coimbra, Diocese de", Dicionário de História Religiosa de Portugal, direção de Carlos Moreira Azevedo, vol. A-C, Lisboa, Circulo de Leitores, 2000, pp. 387-399. Sobre 
de uma das freguesias mais populosas do bispado. Em 1675, segundo um relatório ad limina redigido ao tempo de D. Frei Álvaro de São Boaventura (1672-1683), era a que possuía mais habitantes, com uma população que rondava os 6000 indivíduos $^{6}$. Na centúria seguinte, ainda que tenham ocorrido alguns momentos de crise demográfica, a paróquia manteve elevados índices populacionais ${ }^{7}$.

Como vários autores têm chamado a atenção, a documentação produzida pela atividade visitacional, sobremaneira os livros de devassa onde eram registados os depoimentos dos paroquianos chamados a delatar os "pecados públicos e escandalosos" arrolados nos editais de visita ${ }^{8}$, constitui fonte de enorme valor, oferecendo múltiplas potencialidades de análise, designadamente no campo da história social e das mentalidades?

o arcediagado de Penela cf. António Duarte Brasio, "Arcediagado de Penela", Papel das áreas regionais na formação histórica de Portugal. Actas do colóquio, Lisboa, Academia Portuguesa da História, 1975, pp. 321-327; Maria Alegria Fernandes Marques, "O arcediagado de Penela na Idade Média: algumas notas", Revista de História da Sociedade e da Cultura, n. ${ }^{\circ}$ 8, Coimbra, 2008, pp. 97-143.

6 Vaticano, Archivio Segreto Vaticano, Archivio della Congregazione del Concilio, Relationes Dioecesium, Coimbra, vol. 252, fols. 71-74.

7 Sobre a evolução da população no território que atualmente corresponde ao concelho de Pombal, cf. Ricardo Pessa de Oliveira, Saul António Gomes, Notícias e Memórias Paroquiais Setecentistas - 11. Pombal, Coimbra, Centro de História da Sociedade e da Cultura, Palimage, 2012, pp. 89-102; Ricardo Pessa de Oliveira, Sob os Auspícios do Concílio de Trento: Pombal entre a Prevaricação e o Disciplinamento (1564-1822), Lisboa, Tese de Doutoramento no ramo de História, especialidade de História Moderna, apresentada à Faculdade de Letras da Universidade de Lisboa, 2013, exemplar mimeografado, pp. 25-34, cf. ainda, Joaquim Ramos de Carvalho, José Pedro Paiva, "A Diocese de Coimbra no Século XVIII. População, Oragos, Padroados e Títulos dos Párocos”, Revista de História das Ideias, vol. 11, Coimbra, 1989, pp. 207 e 264.

8 No que respeita ao bispado de Coimbra, cf. Isaías da Rosa Pereira, "As Visitas Paroquiais como Fonte Histórica. Uma Visitação de 1760", Revista da Faculdade de Letras da Universidade de Lisboa, III série, n. ${ }^{\circ}$ 15, Lisboa, 1973, pp. 66-71. Para outros espaços cf. por exemplo, Ana Cristina Machado Trindade, A Moral e o Pecado Público no Arquipélago da Madeira na Segunda Metade do Século XVIII, Funchal, Centro de Estudos de História do Atlântico, Secretaria Regional do Turismo e Cultura, 1999, pp. 200-202.

9 Joaquim Ramos de Carvalho, José Pedro Paiva, "A Evolução das Visitas Pastorais da Diocese de Coimbra nos Séculos XVII e XVIII", Ler História, n. ${ }^{\circ}$ 15, Lisboa, 1989, p. 29. Em Portugal, Isaías da Rosa Pereira e Eugénio dos Santos foram dos primeiros autores a insistir na potencialidade dos livros produzidos pela atividade visitacional, cf. Isaías da Rosa Pereira, "Os Livros das Visitas Pastorais", Actas do V Colóquio Internacional de Estudos Luso-Brasileiros, vol. 2, Coimbra, Gráfica de Coimbra, 1965, pp. 475-484; Idem "As Visitas Paroquiais como Fonte [...]", pp. 11-71; Idem, Subsídios para a História da Diocese de Lisboa no Século XVIII, Lisboa, Academia Portuguesa da História, 1980; Eugénio dos Santos, "Os Livros das Visitas Pastorais da Região Portuense. Questões e Perspectivas de Abordagem", Revista 
O Arquivo da Universidade de Coimbra conserva no seu acervo documentos relativos à atividade visitacional daquela diocese, sendo a maioria da documentação constituída por livros de devassa ${ }^{10}$. No que respeita à paróquia em estudo, existem 55 livros, respeitantes a outros tantos anos, sendo a esmagadora maioria relativos ao século XVII. A primeira visita para a qual existe devassa data de 1649, enquanto a derradeira teve lugar no ano de 1805. Em relação à documentação existente convém esclarecer que a mesma não respeita à totalidade das visitas efetuadas. O cruzamento de fontes, designadamente a análise dos livros de extratos de culpados e dos registos paroquiais, permitiu localizar referências a 24 visitas para as quais não se conservam registos de devassas. A maioria da documentação perdida respeita à primeira metade do século XVIII, já que das 21 visitas que sabemos terem tido lugar nesse período apenas existem registos para oito anos.

3. Nas 55 devassas estudadas contabilizámos 370 casos envolvendo mulheres ${ }^{11}$. A esmagadora maioria das transgressões respeitou a delitos morais, os quais representaram $85,4 \%$. Neste grupo, em que incluem casos de alcoviteirice, amancebamentos, consentimento de comportamentos ilícitos de filhas, problemas conjugais e prostituição, a maioria das denúncias incidiu sobre casos de amancebamento, os quais atingiram $77,2 \%$. O delito da má-língua, abrangendo todas as agressões verbais, tais como calúnias, insultos e pragas ${ }^{12}$, constituiu o segundo caso de

de História, vol. 2, Porto, 1979, pp. 237-244. Refira-se igualmente a tese de licenciatura de António Franquelim Sampaio Neiva Soares defendida em 1972 e do mesmo autor António Franquelim Sampaio Neiva Soares, A Arquidiocese de Braga no Século XVII. Sociedade e Mentalidades pelas Visitações Pastorais (1550-1700), Braga, Edição do Autor, 1997.

10 Joaquim Ramos de Carvalho, José Pedro Paiva, "Reportório das Visitas Pastorais da Diocese de Coimbra séculos XVII, XVIII e XIX", Boletim do Arquivo da Universidade de Coimbra, volume VII, Coimbra, 1985, pp. 111-214. Sobre os diferentes tidos de documentação produzida cf. Joaquim Ramos de Carvalho, As Visitas Pastorais e a Sociedade [...], pp. 23-27.

$11 \mathrm{O}$ número de casos não corresponde ao número de mulheres acusadas, o qual foi inferior. Por exemplo, uma mulher acusada numa mesma visita de andar amancebada e de injuriar os vizinhos representa evidentemente dois casos. Por outro lado, dado que a contabilização foi feita por visita, uma mulher delatada em duas devassas pelo mesmo crime, representou outros tantos casos.

12 Joaquim Carvalho, José Pedro Paiva, “A Evolução [...]”, p. 33. 
visita mais significativo, com 7,3\% do total de situações reportadas. Por seu turno, a não assistência à missa ocupou a terceira posição na hierarquia de delitos, com 2,4\%, seguida dos casos de embriaguez, com 2,2\%. Foram ainda delatadas seis mulheres por inimizades com familiares ou vizinhos $(1,6 \%)$, três por concederem casa de jogo $(0,8 \%)$ e apenas uma por práticas mágicas $(0,3 \%)$.

Entre 1649 e 1805, este quadro geral sofreu transformações que importa especificar. Assim, se as visitas Seiscentistas centraram a sua atenção quase exclusivamente nas questões morais, o cenário modificou-se na centúria seguinte, tendo ocorrido um alargamento da tipologia dos delitos. Esta ampliação foi especialmente significativa durante o governo de D. Miguel da Anunciação (1740-1779). Nesse período, os delitos morais praticados por mulheres baixaram para $64,1 \%$, tendo a má-língua aumentado a sua expressão para $17,4 \%$. Foi igualmente durante o governo deste prelado que, pela primeira vez em Pombal, mulheres foram acusadas de consumo exagerado de vinho, as quais neste período representaram 6,1\%, e de consentir jogo nos seus estabelecimentos, delito que subiu para $3,1 \% 13$.

4. Uma das vertentes da reforma católica respeitou precisamente às condutas dos fiéis, que se pretendiam ajustadas à moral cristã. Relativamente à sexualidade, apenas era considerada lícita quando praticada entre cônjuges, unidos pelo sacramento do matrimónio, e quando tivesse por objetivo a procriação. Todas as restantes práticas sexuais eram tidas por ilícitas, pelo que deviam ser extirpadas.

Como referimos, a esmagadora maioria das situações reportadas aos visitadores respeitou a casos de amancebamento, onde cabiam concubinatos, adultérios e incestos, que evidentemente apresentavam gravidades

13 Para uma visão geral do sucedido na diocese, cf. Joaquim Carvalho, José Pedro Paiva, "A Evolução [...]", pp. 29-41. Para Pombal e freguesias limítrofes cf. Ricardo Pessa de Oliveira, Sob os Auspícios [...], pp. 64-66. Sobre a ação pastoral de D. Miguel da Anunciação cf. Manuel Augusto Rodrigues, "As Preocupações Apostólicas de D. Miguel da Anunciação à luz das suas Cartas Pastorais", A mulher na Sociedade Portuguesa. Visão Histórica e perpectivas actuais. Actas do Colóquio, vol. II, Coimbra, Instituto de História Económica e Social, Faculdade de Letras da Universidade de Coimbra, 1986, pp. 135-166. 
e penalizações distintas. As acusadas eram sobretudo solteiras, a saber $61,1 \%$. Por seu turno, as viúvas corresponderam a $16,8 \%$ do total de amancebadas, enquanto as casadas apenas representaram 15,9\%. As fontes não esclarecem sobre o estado de $6,2 \%$ destas mulheres.

Ao contrário das testemunhas, cuja idade foi quase sempre registada, a das acusadas jamais foi assinalada. Relativamente ao estatuto socioeconómico os dados existentes, apesar de lacunares, apontam essencialmente para gente humilde. Surgem mulheres cujos maridos ou pais eram barbeiros, ferreiros, lavradores, porteiro da vila, marchantes, moleiros, sapateiros e trabalhadores. Quando registada, a profissão das acusadas aponta no mesmo sentido: amas, criadas, estalajadeiras, padeiras, vendeiras, taberneira e tecedeira. Entre os mais desfavorecidos figurou ainda uma escrava. Noutros casos, a condição precária das acusadas é revelada pela pena pecuniária a que foram sujeitas, ou pela ausência da mesma ${ }^{14}$. Refira-se o caso da pombalense Maria, a Cega, denunciada em duas visitas na segunda metade de Seiscentos, em virtude de andar amancebada com Manuel Luís. Após a devassa de 1687, o par, ao comparecer diante do visitador, confessou a culpa e prometeu emenda não sofrendo condenação "por serem muito pobres e miseraveis, que nem para pagarem este termo tem cousa algũa, tanto que se lhes deo esmola"15. Mencione-se ainda o sucedido com Maria, preta, solteira, presa na cadeia da vila. Após a devassa de 1695, na qual foi acusada de trato ilícito com o carcereiro, António Gomes, apenas foi admoestada e sujeita a uma pena espiritual, devido à sua condição de pobre ${ }^{16}$. Ainda assim, algumas das acusadas eram de condição mais elevada. D. Mariana de Sousa e Vasconcelos e D. Jerónima de Sousa e Vasconcelos, delatadas em 1693 e em 1708,

${ }^{14}$ A propósito, refira-se que em 1682, o visitador João Franco de Oliveira, desembargador da Mesa do Despacho, registou que "algũas condenaçois forão moderadas havendo respeito a pobresa", cf. Coimbra, Arquivo da Universidade de Coimbra (A.U.C.), Devassas Penela, liv. 29, fol. 45v [termos das admoestação].

15 Coimbra, A.U.C., Devassas Penela, liv. 33, fol. não numerado. Já em 1683, não haviam sido condenados por serem pobres, cf. Coimbra, A.U.C., Devassas Penela, liv. 30, fol. 9 [termos de admoestação].

16 Em 1696, foram novamente acusados, como se verifica pelo extrato de culpados desse ano, conservado no início do livro da devassa de 1695, cf. Coimbra, A.U.C., Devassas Penela, liv. 46, fol. 235. 
respetivamente, representam os casos extremos, já que pertenciam à principal nobreza da vila ${ }^{17}$.

Os desvios reportados aos visitadores evidenciam distintas situações e estratégias individuais diversas. Como se sabe, com frequência o casamento era precedido de uma promessa realizada pelos nubentes. Acontece que por vezes, após o prometimento, os noivos tinham relações sexuais ou passavam, inclusivamente, a viver maritalmente, o que evidentemente ia contra o determinado no Direito Canónico ${ }^{18}$.

Em finais do século XVI, ainda havia quem considerasse que os esponsórios, seguidos de cópula carnal, constituíam casamento autêntico ${ }^{19}$. Pese os esforços das hierarquias eclesiásticas, parte da população continuou a considerar lícita, ou pelo menos a praticar, a conversação e convivência marital após os esponsais ${ }^{20}$. Por exemplo, a 27 de Outubro de 1722, foram denunciados Joana Lopes, filha de Manuel Lopes e de Maria Mendes, ambos já falecidos, e Manuel Rodrigues, filho de Miguel Rodrigues e de sua mulher Isabel João, também já falecida, todos residentes no Travasso. Segundo o testemunho de Manuel Antunes, lavrador do dito lugar, havia três meses que Joana e Manuel, ambos solteiros, estavam jurados para casar, existindo fama de terem tido, entretanto, cópula. No fim da visita, o casal, provavelmente por ter sido registada uma única denúncia, não foi sequer pronunciado. Seja como for, pouco depois a 18 de Novembro de 1722, contraíram de facto matrimónio ${ }^{21}$. Se desta feita o casamento acabou

${ }^{17}$ A primeira era filha de António de Sousa e Vasconcelos e de D. Jerónima. A segunda era filha de Nicolau de Sousa e Vasconcelos, irmão da referida D. Mariana, cf. Coimbra, A.U.C., Devassas Penela, liv. 42, fols. 222-223; Lisboa, Arquivo Nacional Torre do Tombo (A.N.T.T.), Inquisição de Coimbra, proc. 6928.

18 Federico Palomo, A Contra-Reforma em Portugal 1540-1700, Lisboa, Livros Horizonte, 2006, pp. 117-118. Sobre os esponsais cf. Maria da Conceição Meireles Pereira, "Os Esponsais - Forma e Significado no Contexto da Sociedade Portuguesa de Setecentos", Revista da Faculdade de Letras, História, série II, vol. 5, Porto, 1988, pp. 189-210.

19 Constituições Synodaes do Bispado de Coimbra, Coimbra, António de Mariz, 1591, fol. $34 \mathrm{v}$.

20 Cf, por exemplo, Constituições Synodaes do Bispado de Coimbra, Coimbra, António de Mariz, 1591, fols. 34v-35.

${ }^{21}$ Leiria, Arquivo Distrital de Leiria, (A.D.L.), Registos Paroquiais, Pombal, Casamentos, IV-42-D-5, fol. 260v. 
por acontecer noutros casos tal não sucedia, o que representava um problema acrescido 22 .

Em lugares de reduzida dimensão, como os que compunham a freguesia em estudo, com alguma frequência os nubentes encontravam-se nos graus de parentesco proibidos pela Igreja, mas suscetíveis de dispensa ${ }^{23}$. A documentação estudada demonstrou que parte dos noivos, enquanto aguardava a referida licença, passava a coabitar maritalmente, gerando inclusivamente prole. O caso de Maria e de Diogo, ambos solteiros e moradores no lugar do Travasso, denunciados em 1784, é paradigmático. O casal havia requerido a dispensa há seis anos "e com o titulo de cazamento continuão na sua incestuoza mancebia, frequentando a caza hum do outro" ${ }^{4}$. Entretanto, já havia tido três filhos, estando a caminho um quarto rebento. Na verdade, o desejo de obter a dispensa matrimonial poderá ter contribuído para o avolumar deste tipo de transgressão, pois havia consciência que a Igreja, por norma, dispensava quando tinha notícia da existência de relações sexuais entre parentes ${ }^{25}$.

Uma das principais características do casamento cristão ocidental residiu no seu carácter de indissolubilidade. Desde que recebidos de forma legal, os cônjuges ficavam impossibilitados de contrair novo enlace. Existiam apenas duas possibilidades legais de tornar a casar: obter declaração de

22 Por exemplo, em 1713 Manuel de Oliveira, oficial de pedreiro, andava amancebado com Teresa Gomes, viúva, da rua das Nogueiras, com quem prometera casar, caso a sua esposa falecesse. Segundo Bartolomeu da Silva, testemunha da devassa, o dito Manuel, que na verdade parecia chamar-se Manuel João, enganara a amante, "tendo principio desta illicita amizade por dizer hera viuvo e com ella havia de cazar, sendo que elle he cazado e ela emfadada de que a tivesse enganado o fes meter na cadea para haver de lhe pagar algum dinheyro que lhe devia, porem despois se compadeceu delle logo e outra vez o admite, como de antes, em sua caza", cf. Coimbra, A.U.C., Devassas Penela, liv. 54 , fols. $5 \mathrm{v}$ e $17 \mathrm{v}$.

23 Joaquim Ramos de Carvalho, "As Sexualidades", História da Vida Privada em Portugal, direção de José Mattoso, [vol. 2], A Idade Moderna, coordenação de Nuno Gonçalo Monteiro, [Lisboa], Círculo de Leitores, Temas e Debates, 2010, p. 110.

${ }^{24}$ Coimbra, A.U.C., Devassas Penela, liv. 54, fol. $245 \mathrm{v}$.

25 João Rocha Nunes, A Reforma Católica na Diocese de Viseu (1552-1639), Tese de Doutoramento em Letras, área de História, especialidade de História Moderna, apresentada à Faculdade de Letras da Universidade de Coimbra, Coimbra, 2010, exemplar mimeografado, pp. 250-251. 
nulidade do primeiro matrimónio, o que apenas sucedia em situações particulares, ou o falecimento de um dos cônjuges ${ }^{26}$. Na inexistência de uma das condições referidas, aquele que pretendesse reconstruir a vida com alguém que não o legitimo cônjuge, teria de optar por uma de várias situações ilícitas, entre as quais figuravam o amancebamento e a bigamia. A análise da documentação evidenciou que para algumas das acusadas o recurso a um relacionamento ilícito, afigurava-se como forma de refazer a vida. Não raras vezes, existe indicação da ausência prolongada do marido, que podia estar inclusivamente morto. Assim, em 1673, Manuel Lopes ao delatar a relação ilícita de Madalena Fernandes com Simão de Faria, o Vinagreiro, declarou existir dúvida "se o marido he vivo ou se he morto, e que os ditos complices tem feito promessa de cazar" ${ }^{27}$. Não muito diferente parece ter sido o caso de Maria Francisca, delatada em 1722, cujo marido, José Francisco, estava ausente há $15 \operatorname{anos}^{28}$.

Além das situações já evidenciadas, as fontes esclarecem outros motivos que concorreram para a transgressão às normas instituídas, nomeadamente a submissão da acusada face ao cúmplice. O caso que melhor retrata esta situação é o de Isabel, escrava mulata, delatada nas visitas de 1673 e de 1674, por andar amancebada com Manuel Leal, solteiro, capitão da vila e seu proprietário, de quem tivera dois filhos ${ }^{29}$. Evidentemente que a escravidão de Isabel tornava-a vulnerável às investidas do seu proprietário, que desta forma, além de satisfazer a sua concupiscência aumentava o número de escravos ${ }^{30}$. Se num primeiro momento o par foi admoestado

26 Não obstante, a Igreja entendia que os viúvos não deviam contrair novo enlace. Assim sendo, se não proibia nova união, também não a encorajava. Recorde-se que no segundo matrimónio não era concedida a bênção sacerdotal, cf. Isabel M. R. Mendes Drumond Braga, A Bigamia em Portugal na Época Moderna. Sentir Mal do Sacramento do Matrimónio?, Lisboa, Hugin, 2003, p. 91. "E declaramos, que as benções se não fação quando são viuvos ambos, ou a molher, porque sendo elle viuvo \& ella, não se the devem nem podem fazer", cf. Constituições Synodaes do Bispado de Coimbra, Coimbra, António de Mariz, 1591, fol. 35v.

27 Coimbra, A.U.C., Devassas Penela, liv. 22, fol. 220.

28 Coimbra, A.U.C., Devassas Penela, liv. 56, fol. $584 v$.

29 Coimbra, A.U.C., Devassas Penela, liv. 22, fols. 219v-220v, 221v, 224v e liv. 23, fols. $134 \mathrm{v}$ e $135 \mathrm{v}$.

30 Sobre esta temática cf. Jorge Fonseca, Escravos e Senhores na Lisboa Quinhentista, Lisboa, Colibri, 2010, pp. 341-349. 
e sujeito a uma pena pecuniária de 400 réis, cada um, em 1674, as autoridades eclesiásticas conscientes da particularidade do caso, obrigaram que o capitão Manuel Leal comparecesse com Isabel perante o visitador "pera fazer termo de vender a escrava"31.

Refira-se por último as frequentes situações envolvendo homens da elite local e mulheres de estratos inferiores, nas quais não raras vezes existem indícios de dependências económicas ${ }^{32}$. Este tipo de relacionamento, em que o casamento se afigurava impossível, era do conhecimento das respetivas famílias podendo ser, em localidades de reduzida dimensão, socialmente tolerado 33 . Atentemos num caso concreto. $\mathrm{Na}$ visita de 1718, António da Fonseca de Mancelos (1678-1748), figura grada da terra, que entre outras instituições veio a dirigir a Misericórdia local na década de trinta do século XVIII, foi acusado de andar amancebado com Antónia dos Santos, solteira, natural do Souto, freguesia de Vila Cã, filha de Manuel Pimenta, criada de uma Teresa, com quem também terá tido um caso. Da relação entre António e Antónia nasceu Diogo, batizado a 5 de Março de 1718. Pelo assento de batismo, além de constatarmos que o progenitor foi claramente identificado, verificamos que os familiares de António participaram na cerimónia, tendo Simão de Mancelos da Fonseca apadrinhado a criança ${ }^{34}$. Mais tarde, a 16 de Dezembro de 1737, Diogo acabaria por ser legitimado e chegaria, também ele, à provedoria da Misericórdia pombalense ${ }^{35}$. Registe-se ainda que este relacionamento e posterior legitimação de Diogo possibilitaram uma enorme melhoria de vida a Teresa, a ponto de, em 1754, viver na companhia do filho na sua quinta do Souto, arrabalde da vila de Pombal, e ter apadrinhado diversas crianças ${ }^{36}$.

\footnotetext{
31 Coimbra, A.U.C., Devassas Penela, liv. 23, fol. 225.

${ }^{32}$ A propósito desta realidade cf. Joaquim Ramos de Carvalho, "As Sexualidades [...]", p. 110.

33 Joaquim Ramos de Carvalho, "As Sexualidades [...]", p. 110.

${ }^{34}$ Leiria, A.D.L., Registos Paroquiais, Pombal, Baptismos, IV-42-B-71, fol. 635.

35 Coimbra, A.U.C., Devassas Penela, Extractos de culpados, liv. 4, fol. 296. Leiria, A.D.L., Registos Paroquiais, Pombal, Baptismos, IV-42-B-71, fol. 635. Lisboa, A.N.T.T., Chancelaria de D. João V, Perdões e Legitimações, liv. 139, fols. 208v-209.

36 Leiria, A.D.L., Registos Paroquiais, Pombal, Baptismos, IV-42-B-72, fols. 551 e 581 v.
} 
5. Na Época Moderna, a Igreja e as autoridades seculares reformularam a postura face à prostituição. A tolerância que a prática havia conhecido na Idade Média, período em que, ainda que desaprovada, era considerada um mal necessário e inevitável, diminuiu consideravelmente 37.

Nas visitas estudadas, a prostituição representou 10,5\% do total de casos denunciados e $12,3 \%$ dos delitos morais. A esmagadora maioria das acusadas era solteira, a saber $82,1 \%$. Apenas foram registadas três viúvas e duas casadas, permanecendo desconhecida a situação de duas moças delatadas em 1759 e identificadas pela alcunha Estacas, ainda que neste caso o termo "moça” remeta para alguém jovem que, muito provavelmente, ainda não havia contraído matrimónio. No que respeita às casadas, cabe referir que nenhuma coabitava com o cônjuge. Luísa Gomes delatada por diversos delitos morais, entre 1657 e 1665, estava separada do marido, Domingos Francisco, que residia em Leiria. Na visita de 1658, o padre Manuel Nunes, afirmou que Luísa era a responsável pela separação "per que sempe teve fama de má molher assy em solteira como depois de cazada e de prezente tem a mesma fama e de dia ve elle testemunha que alguns homens vão a sua caza falar com ella"38. Mais tarde, em 1745, Angélica Joaquina, natural de Coimbra, mas residente há dois ou três anos na Pelariga, em casa de uma tia, tinha o marido ausente nas partes ultramarinas.

Relativamente à condição socioeconómica das acusadas as informações são igualmente lacunares. Na visita de 1664, foi denunciada uma viúva, cujo nome não foi registado, moradora em Pombal, que havia sido casada com o Gago de alcunha, que fora marchante ${ }^{39}$. Por sua vez, em 1686, foi acusada Maria Lopes, solteira, filha de Manuel Francisco, porteiro da vila ${ }^{40}$. Muito

37 Sobre a prostituição na Idade Média cf. Mario Pilosu, A Mulher, a Luxúria e a Igreja na Idade Média, tradução de Maria Dolores Figueira, Lisboa, Editorial Estampa, 1995, pp. 73-98. Para o caso português, cf. Maria Ângela V. da Rocha Beirante, "As Mancebias nas Cidades Medievais Portuguesas", A Mulher na Sociedade Portuguesa. Visão Histórica e Perspectivas Actuais. Actas do Colóquio, vol. 1, Coimbra, Instituto de História Económica e Social, Faculdade de Letras da Universidade de Coimbra, 1986, pp. 221-241. Sobre a evolução da atitude face à prostituição no reino vizinho, cf. Ainhoa Fernández Sobremazas, "Prostitutas en la España Moderna", Historia 16, n. ${ }^{\circ}$ 357, 2006, pp. 8-37.

38 Coimbra, A.U.C., Devassas Penela, liv. 9, fols. 106-106v.

39 Coimbra, A.U.C., Devassas Penela, liv. 14, fol. 187v.

40 Coimbra, A.U.C., Devassas Penela, liv. 32, fols. 243v, 244v, 246 e $246 v$. 
mais tarde, em 1757, duas pessoas acusaram Francisca Marques, vendeira de água ardente ${ }^{41}$. Por seu turno, Bernarda e Feliciana, denunciadas em 1762, eram filhas de António Gomes, carcereiro da vila ${ }^{42}$. Outros elementos permitem verificar que se tratava de mulheres de baixa condição social. A 4 de Junho de 1692, Maria Corada, fez termo em terceiro lapso, não sendo condenada por ser pobre ${ }^{43}$. Algo idêntico sucedeu com Luísa, solteira, moradora em Pombal, delatada em 1695, que por ser pobre foi admoestada e teve pena espiritual ${ }^{44}$. Por outro lado, várias das acusadas eram órfãs de pai, situação que poderá ter obrigado à utilização do sexo como meio de subsistência, ou pelo menos, como um complemento.

Em Pombal, as acusadas achavam-se dispersas por diversas ruas da vila e lugares da freguesia. Antónia, a Maracota, solteira, filha de Maria das Neves, viúva, delatada em 1668, era moradora na rua da Azinhaga 45 . Pouco depois, em 1676, foi denunciada Maria, filha de Maria Gaspar, viúva, residente na rua da Estalagem ${ }^{46}$. Na mesma rua, habitava Ana Botelha delatada em $1692^{47}$, ano em que foi ainda denunciada a já mencionada Maria Corada, moradora na praça velha, atrás da igreja ${ }^{48}$. Quanto aos restantes lugares da freguesia destaque para a Pelariga e para o Santorum, onde residiam quatro e três das mulheres denunciadas, respetivamente.

Os espaços do delito eram variados. As acusadas aliciavam os seus clientes em distintos locais, designadamente em estradas, em fontes e nas margens do rio. Os encontros sexuais, propriamente ditos, tinham preferencialmente lugar nas habitações das delatadas. Vejamos alguns exemplos. Catarina, a Corada, e Ana, sua prima direita, igualmente co-

41 Coimbra, A.U.C., Devassas Penela, liv. 66, fol. 303v.

42 Coimbra, A.U.C., Devassas Penela, liv. 68, fol. 188.

43 Coimbra, A.U.C., Devassas Penela, liv. 41, fol. não numerado [termos].

44 Coimbra, A.U.C., Devassas Penela, liv. 46, fol. 235v. Refira-se ainda uma Maria, solteira, a Torta de apelido, residente em Pombal, acusada na visita de 1741, ano para o qual não se conserva livro de devassa, que foi admoestada sem multa em virtude da sua pobreza, cf. Coimbra, A.U.C., Devassas Penela, Extractos de culpados, liv. 7, fol. 119.

45 Coimbra, A.U.C., Devassas Penela, liv. 18, fols. 69-69v.

46 Coimbra, A.U.C., Devassas Penela, liv. 24, fol. 259.

47 Coimbra, A.U.C., Devassas Penela, liv. 41, fols. 163-163v.

48 Coimbra, A.U.C., Devassas Penela, liv. 41, fols. $172 \mathrm{v}$ e $174 \mathrm{v}$. 
nhecida por aquela alcunha, delatadas em 1702, ofereciam-se a diversos homens no rio, entenda-se nas suas margens, na fonte e em qualquer parte pública ${ }^{49}$. Por sua vez, as irmãs Isabel e Felizarda, filhas de João Rodrigues da Cova, moradoras no lugar do Santorum, delatadas em 1736, recebiam vários indivíduos na sua habitação "e ahy estam fazendo galhofas e maganagens com grande escandalo" 50 . Mais tarde, em 1745, Ana Guardada, viúva, do lugar da Venda da Cruz, foi delatada por ser "muito chocareyra e muito amiga de conversar e galhofear com homens admettindo os em sua caza" 51 .

No que toca à clientela destas mulheres, as fontes indicam que estas eram procuradas quer por conterrâneos, quer por indivíduos procedentes de outras paragens, sendo mencionados homens de mau procedimento, soldados e vadios. Isabel, solteira, moradora no lugar do Passo, filha de João Francisco, já falecido, delatada em 1686 e em 1692, recebia em sua casa "muitos homens asim da terra como de fora" 52 . Por seu turno, em 1745, Ana Maria, solteira, que viera da freguesia de Vermoil, bispado de Leiria, moradora na Ranha de Baixo há cerca de um ano, admitia na sua residência diversos elementos do sexo masculino, especialmente do bispado de Leiria ${ }^{53}$. Em 1781, Maria, solteira, filha de Manuel Domingues, também ele já defunto, acolhia na sua habitação "homens de mao procedimento e soldados com escandallo de seus vezinhos" 54 . No mesmo ano, Margarida, solteira, filha de João Ferreira e de Maria dos Santos, do lugar do Santorum, foi acusada de andar pelas estradas "com homens vadios e de mão procedimento recolhendo-os em sua caza" 55 . Entre os que

49 Coimbra, A.U.C., Devassas Penela, liv. 49, fol. 40. Não raras vezes as fontes surgem como locais onde ocorriam relações sexuais, cf. Paulo Drumond Braga, "Dados para o estudo da homossexualidade em Portugal no século XVII: o processo inquisitorial de Manuel de Andrade", Vértice, II série, ${ }^{\circ}$ 58, Lisboa, Janeiro-Fevereiro de 1994, p. 127; Idem, "Cheiram os homens a mulheres; não a Marte, mas a Vénus. Sociabilidades Homossexuais (séculos XVI-XVII)", Lusíada, História, série II, n. ${ }^{4}$ 4, Lisboa, 2007, p. 192.

\footnotetext{
50 Coimbra, A.U.C., Devassas Penela, liv. 60, fols. 395-395v.

51 Coimbra, A.U.C., Devassas Penela, liv. 62, fol. 123v.

52 Coimbra, A.U.C., Devassas Penela, liv. 41, fols. 159v-160.

53 Coimbra, A.U.C., Devassas Penela, liv. 62, fols. 136v e 147.

54 Coimbra, A.U.C., Devassas Penela, liv. 74, fols. 111v-112.

55 Coimbra, A.U.C., Devassas Penela, liv. 74, fols. 117, 122-122v.
} 
mantinham contactos sexuais com estas mulheres figuravam igualmente indivíduos de estatuto mais elevado, caso de Manuel da Fonseca, feitor da Quinta da Gramela, denunciado em 1745, por manter uma relação com a já referida Ana Guardada 56 .

Quanto aos preços praticados por estas mulheres as fontes são praticamente omissas. Sabemos apenas que em 1692, uma testemunha ao acusar Esperança, solteira, natural da freguesia de Colmeias, bispado de Leiria, moradora nos Crespos, termo de Pombal, referiu que "os tempos passados veio ahi hum homem o qual lhe dera hum tostão por usar della mal" 57 , ou seja, uma moeda de prata no valor de 100 réis ${ }^{58}$, quantia verdadeiramente insignificante. Para se ter ideia, no ano anterior Maria Carvalha, solteira, moradora na rua do Rio, após ter sido acusada de andar amancebada com Domingos Antunes, boticário da vila, foi admoestada pelo pároco, o qual atendendo à "sua confissão e protesto da emenda e visto a sua pobreza a condenou em duzentos e corenta reis" 59 .

6. Concluída a devassa tinha lugar a pronúncia da sentença. O tipo de pena a aplicar variava, evidentemente, consoante o tipo de delito e o grau de reincidência. Por norma, as acusadas limitavam-se a assinar um termo de admoestação, em que prometiam emenda, termo que podia ou não ser acompanhado de uma pena pecuniária, a arbítrio do visitador ${ }^{60}$. Como verificámos, em alguns casos a multa podia ser substituída por uma pena espiritual. Na maioria das ocasiões, a admoestação tinha lugar perante o visitador, na própria paróquia ou em igreja vizinha. O termo podia

56 Coimbra, A.U.C., Devassas Penela, liv. 62, fols. 127, 127v-128, 144, 148, 152v-153, 154. Este relacionamento ilícito já havia sido denunciado em 1741, quando o marido de Ana, João Gonçalves, ainda era vivo. Na ocasião, o feitor fez termo em primeiro lapso de concubinato, enquanto Ana foi admoestada em segredo pelo pároco, cf. Coimbra, A.U.C., Devassas Penela, Extractos de culpados, liv. 7, fol. 118v.

57 Coimbra, A.U.C., Devassas Penela, liv. 41, fol. 177.

58 Avelino de Freitas de Meneses, "As Finanças", Nova História de Portugal, direção de Joel Serrão e A.H. de Oliveira Marques, vol. VII, Portugal. Da Paz da Restauração ao Ouro do Brasil, coordenação de Avelino de Freitas de Meneses, Lisboa, Editorial Presença, 2001, p. 362.

59 Coimbra, A.U.C., Devassas Penela, liv. 37, doc. avulso.

60 Joaquim Ramos de Carvalho, As Visitas Pastorais e a Sociedade [...], pp. 123-125; António Franquelim Sampaio Neiva Soares, A Arquidiocese de Braga [...], pp. 631-632. 
ainda ser assinado em Coimbra, na Mesa episcopal, diante do provisor do bispado. Acrescente-se que em alguns casos, sobretudo tratando-se de mulheres adúlteras, a admoestação poderia ocorrer em segredo, perante o vigário da paróquia, o que era justificado pelo receio de que o marido, ao tomar conhecimento da traição, atentasse contra a vida da esposa ${ }^{61}$.

Apenas os casos mais graves, especialmente as relações incestuosas, originaram processo no auditório eclesiástico, designado por livramento e que compreendia distintas modalidades. Por outro lado, aquelas que após uma terceira admoestação persistiram na sua conduta errónea foram sujeitas a um processo no juízo eclesiástico. Desta forma, verifica-se que as denúncias reportadas em sede de visita pastoral constituíram como que um processo inicial que em situações de maior gravidade suscitou a abertura de processo judicial ${ }^{62}$.

Relativamente à paróquia de Pombal, e no que respeita a mulheres, apenas $8,4 \%$ dos casos denunciados em visita foram pronunciados a livramento. Cabe referir que nem todas chegaram a ser realmente julgadas. Joana Jorge delatada na visita de 1655 , por consentir no comportamen-

61 Constituições Synodaes do Bispado de Coimbra, Coimbra, António de Mariz, 1591, fol. 197. Recorde-se que as ordenações do reino possibilitavam o assassinato da mulher adúltera, conferindo proteção ao marido, cf. Ordenações Filipinas, reprodução fac-símile da edição de 1870, livro V, Lisboa, Fundação Calouste Gulbenkian, 1985, título XXXVIII, pp. 1188-1189. Esse desfecho devia suceder com relativa frequência. Em 1723, o teatino Bluteau, ao pregar um sermão numa igreja lisboeta afirmou que "qualquer sombra de infidelidade no tálamo conjugal afia o punhal para o desagravo e o matar mulheres é ponto de honra", cf. Maria Antónia Lopes, Mulheres, Espaço e Sociabilidade. A transformação dos papéis femininos em Portugal à luz de fontes literárias (segunda metade do século XVIII), Lisboa, Livros Horizonte, 1989, p. 35.

62 A propósito desta realidade cf. João Rocha Nunes, "Crime e castigo: 'Pecados Publicos' e Disciplinamento Social na Diocese de Viseu (1684-1689)”, Revista de História da Sociedade e da Cultura, vol. 6, Coimbra, 2006, pp. 177-213; Idem, A Reforma Católica [...], pp. 315-324. Sobre o auditório eclesiástico de Coimbra, cf. Jaime Ricardo Gouveia, "Quod non est in actis, non est in mundo: Mecanismos de Disciplina Interna e Externa no Auditório Eclesiástico de Coimbra", Revista de História da Sociedade e da Cultura, n. ${ }^{\circ}$ 9, Coimbra, 2009, pp. 179-204; Idem, "A Configuração Organizacional dos Auditórios Eclesiásticos: Perfis, Competências e Funções dos Oficiais da Justiça. O caso de Coimbra”, texto apresentado ao XXX Encontro da Associação Portuguesa de História Económica e Social, disponível em linha em, http://www.iseg.utl.pt/aphes30/docs/progdocs/JAIME\%20RICARDO\%20GOUVEIA. pdf (consultado em 4 de Novembro de 2014). Para a diocese do Funchal, cf. Ana Cristina Machado Trindade, Dulce Manuela Teixeira, "O Regimento dos Auditórios Eclesiásticos do Bispado do Funchal (1589)", Lusitania Sacra, 2. ${ }^{a}$ série, n. ${ }^{\circ}$ 15, Lisboa, 2003, pp. 289-330; Idem, O Auditório Eclesiástico da Diocese do Funchal. Regimento e espólio documental do século XVII, Funchal, Instituto Superior de Administração e Línguas, 2003. 
to ilícito da filha, Isabel, com o padre frei Simão Correia, foi perdoada pelo cabido sede vacante por constar que a filha havia contraído matrimónio ${ }^{63}$. Por motivo semelhante, mas muito mais tarde, D. Miguel da Anunciação, por despacho de 6 de Julho de 1746, perdoou o livramento a Manuel Gonçalves e a Mariana Francisca que haviam sido postos na visita do ano anterior por concubinato incestuoso ${ }^{64}$. Ou seja, nestes casos o casamento, pese embora precedido de trato ilícito, funcionou como circunstância atenuante.

Apesar dos processos terem desaparecido ou ainda não terem sido localizados, a análise dos livros de extratos de culpados e dos livros de devassa permitiu conhecer o registo sumário das sentenças de dez mulheres, moradoras na freguesia de Pombal. Todas as sentenças conhecidas datam do século XVIII, sendo a primeira de 1700 e a derradeira de 1782. A totalidade dos processos foi originada por delitos morais, designadamente seis casos de incesto, duas mancebias com clérigos, um concubinato cuja natureza não foi especificada e um caso de alcoviteirice.

Relativamente aos casos de incesto, as constituições da diocese estipulavam que os leigos que cometessem o delito, em primeiro grau de consanguinidade, fossem punidos com quatro anos de degredo para as galés e multa pecuniária a arbítrio do vigário-geral. Tratando-se de nobre ou indivíduo de idade avançada, como tal inútil para as galés, a pena seria comutada por degredo para o Brasil, por um período de sete anos. Nos restantes graus, por via de consanguinidade ou afinidade, o réu seria sujeito a degredo e a pena pecuniária, segundo o grau de parentesco, o estatuto social e as circunstâncias do crime ${ }^{65}$. Relativamente às mulheres, o texto especificava que fossem condenadas a degredo e prisão "segundo o grau em que for, \& malicia que contra ellas se provar, tendo-se

63 Coimbra, A.U.C., Devassas Penela, liv. 7, fols. 117-117v. Casou a 23 de Dezembro de 1655, na ermida de Nossa Senhora do Cardal, com Manuel Luís, da paróquia de Vila Cã, termo de Pombal, cf. Leiria, A.D.L., Registos Paroquiais, Pombal, Casamentos, IV-42-D-5, fol. 24.

64 Coimbra, A.U.C., Devassas Penela, liv. 62, fol. 156v. O matrimónio teve lugar a 8 de Setembro de 1755, na matriz de São Martinho, cf. A.D.L., Registos Paroquiais, Pombal, Casamentos, IV-42-D-5, fols. 404v-405.

65 Constituições Synodaes do Bispado de Coimbra, Coimbra, António de Mariz, 1591, fols. 198-198v. 
respeyto a sua fraqueza, o que ficará ao arbitrio do nosso vigayro" 66 . Recorde-se que a mulher, a quem o discurso normativo cristão associava a maldade e a inferioridade, gozava em virtude de tal discriminação, de um estatuto jurídico especial ${ }^{67}$. Em conformidade, o vigário-geral deveria ter em conta a sua natural fraqueza comutando a pena de degredo ou designando local onde o pudesse melhor cumprir, como esmiuçava por exemplo o texto normativo da diocese de Portalegre ${ }^{68}$.

Nas sentenças conhecidas, nenhuma compreendendo incesto entre familiares diretos, só por duas vezes as acusadas foram sentenciadas a degredo, em ambos os casos por período de um ano, uma para o bispado da Guarda, outra para a diocese de Leiria. Cinco foram sujeitas a pena pecuniária, que oscilou entre 800 réis e 6.000 réis. Distinta foi a sentença proferida a 24 de Novembro de 1719, contra Maria das Neves Freire, do lugar da Estrada, que por andar amancebada com Damião Furtado Morais, seu parente em segundo e terceiro graus de afinidade, foi condenada em dois meses de aljube e obrigada a pagar as custas do processo ${ }^{69}$.

Relativamente aos demais amancebados, as constituições, que não distinguiam entre casados e solteiros, decretavam que aquele que depois de admoestado três vezes reincidisse no delito fosse preso e condenado em dez cruzados, ou seja, 4.000 réis $^{70}$, para a Sé e meirinho, e nas mais penas que merecesse, podendo ainda vir a ser degredado ${ }^{71}$. Pese o determinado, a 31 de Janeiro de 1780, Maria das Neves, viúva, por ilícita amizade com Manuel Nogueira, foi condenada em 8.000 réis e a um ano de degredo para o bispado de Portalegre ${ }^{72}$.

66 Constituições Synodaes do Bispado de Coimbra, Coimbra, António de Mariz, 1591, fol. 198v.

67 Sobre o estatuto da mulher cf. António Manuel Hespanha, História das Instituições: Épocas Medieval e Moderna, Coimbra, Almedina, 1982, p. 229. A propósito do discurso normativo cristão sobre a mulher cf. Maria Antónia Lopes, Mulheres, Espaço e Sociabilidade [...], pp. 17-45.

68 Constituições Synodaes do Bispado de Portalegre, Portalegre, Jorge Roiz, 1632, fol. 237v..

69 Coimbra, A.U.C., Devassas Penela, Extractos de culpados, liv. 1, fol. 55v.

70 Avelino de Freitas de Meneses, "As Finanças [...]", p. 362.

71 Constituições Synodaes do Bispado de Coimbra, Coimbra, António de Mariz, 1591, fols. 199-199v.

${ }^{72}$ Coimbra, A.U.C., Devassas Penela, Extractos de culpados, liv. 1, fol. 55v. 
Ao contrário das ordenações do reino, as constituições não especificavam as penas a aplicar às barregãs de clérigos. Assim, as sentenças contra as duas mulheres acusadas de trato ilícito com eclesiásticos foram bastante díspares. A 10 de Agosto de 1737, Teresa dos Santos, solteira, do lugar do Santorum, delatada na visita de 1736 por andar amancebada com o padre Manuel da Cunha ( $4 .^{\circ}$ lapso), foi condenada em 4.000 réis e a um ano de degredo para fora do bispado ${ }^{73}$. Muito mais rígida foi a sentença proferida a 20 de Junho de 1757, contra Mariana da Assunção Botelha, natural da freguesia de Tapéus, criada do vigário proprietário de Pombal frei José Rodrigues Maia, com o qual andava amancebada há mais de duas décadas ${ }^{74}$. Semelhante tenacidade motivou que fosse condenada em 16.000 réis, a três anos de degredo para o bispado da Guarda e a pagar as custas do processo. Não obstante, recorreu da sentença para a Legacia, tendo sido absolvida por sentença de 4 de Novembro de 1757 , ficando apenas obrigada a pagar o custo dos autos ${ }^{75}$. Como se sabe, o auditório funcionava como tribunal de primeira instância, sendo permitido recorrer da sentença para o tribunal metropolitano, que no caso da diocese de Coimbra era a relação de Braga. Era ainda exequível apelar, como demonstra o caso em apreço, para o tribunal do Núncio e eventualmente para Roma ${ }^{76}$. Não obstante, o recurso exigia meios financeiros consideráveis ${ }^{77}$. No caso em análise, tratando-se de uma criada parece evidente que o recurso apenas foi possível por intermédio do dito vigário, seu cúmplice.

No que toca às sentenças, há ainda a registar o arquivamento de um processo. Tratou-se dos autos relativos a Domingas Rodrigues, viúva, que havia sido acusada de alcovitar a sua filha Josefa. Muito provavelmente

\footnotetext{
73 Coimbra, A.U.C., Devassas Penela, liv. 60, fol. 400v.

${ }^{74}$ Sobre este clérigo e o conflito que protagonizou com o bispo D. Miguel da Anunciação, cf. Ricardo Pessa de Oliveira, Sob os Auspícios de Trento [...], pp. 106-112.

75 Coimbra, A.U.C., Devassas Penela, Extractos de culpados, liv. 9, fol. 73.

76 Acrescente-se a possibilidade de recorrer para os tribunais régios, cf. Joaquim Ramos de Carvalho, As Visitas Pastorais e a Sociedade [...], pp. 148-151; João Rocha Nunes, "Crime e Castigo [...]", pp. 184-185; Jaime Ricardo Gouveia, "Quod non est [...]", pp. 185-186.

77 Jaime Ricardo Gouveia, "Quod non est [...]”, p. 190.
} 
terá conseguido provar que as testemunhas de acusação eram suas inimigas, acabando absolvida por sentença de 30 de Agosto de $1723^{78}$.

Segundo os dados existentes, quer parecer que o processo de livramento corria de forma relativamente célere. Nos quatro casos em que conhecemos a data da visita em que a ré foi delatada e a data da sentença, verificamos que por três ocasiões decorreram entre onze e doze meses entre as duas datas, enquanto o processo mais moroso prolongou-se por 20 meses.

Após a leitura da sentença, houve quem tivesse alcançado a comutação das penas, permanecendo desconhecido se tal resultou de requerimento da própria sentenciada. Ainda assim, nos dez casos conhecidos tal apenas ocorreu por uma ocasião. Tratou-se de Maria Teresa, que havia sido condenada em 1757, a uma pena pecuniária no valor de 6.000 réis e a um ano de degredo para o bispado da Guarda, além das custas do processo $^{79}$. Acabou por pagar somente 3.000 réis, tendo sido perdoado o degredo e o pagamento das custas ${ }^{80}$.

Uma das questões que se coloca respeita ao cumprimento das penas. Seriam de facto cumpridas? Na documentação estudada existem determinadas notas que evidenciam que tal nem sempre sucedia, pelo menos no imediato. Se ao lado do registo da condenação de Isabel, solteira, filha de Manuel João, do lugar dos Carvalhais, existe indicação de ter pago os 2.000 réis a que havia sido sentenciada ${ }^{81}$, noutros casos foi registada uma advertência, dando conta de que faltava cumprir parte ou a totalidade da sentença. A já mencionada Maria das Neves, condenada em 1780, a pagar 8.000 réis e a um ano de degredo para o bispado de Portalegre, devia ainda (desconhecemos a data) o degredo ${ }^{82}$. Por seu turno, Maria, processada em 1782 a uma pena de 4.000 réis e a cumprir um ano de degredo para a diocese leiriense, devia tudo ${ }^{83}$. A escassez de

78 Coimbra, A.U.C., Devassas Penela, Extractos de culpados, liv. 1, fol. 55v.

79 Coimbra, A.U.C., Devassas Penela, Extractos de culpados, liv. 8, fol. 84.

${ }^{80} \mathrm{Na}$ diocese de Viseu, parte considerável dos sentenciados entre 1684 e 1689, obteve perdão do degredo, cf. João Rocha Nunes, "Crime e Castigo [...]", p. 204.

81 Coimbra, A.U.C., Devassas Penela, Extractos de culpados, liv. 3, fol. 63.

82 Coimbra, A.U.C., Devassas Penela, Extractos de culpados, liv. 1, fol. 55.

83 Coimbra, A.U.C., Devassas Penela, Extractos de culpados, liv. 3, fol. 63. 
dados, aliada ao facto de permanecem desconhecidos os dispositivos que a justiça episcopal possuía para obrigar ao cumprimento das sentenças proferidas, não permite retirar grandes ilações.

Importa por último, tentar aferir as verdadeiras consequências da sentença para as prevaricadoras? O conjunto de penas aplicadas teria com toda a certeza um forte impacto no seu quotidiano, nomeadamente a nível económico. Tratando-se sobretudo de gente humilde, pertencente aos baixos estratos sociais, seria dificultoso pagar as penas pecuniárias a que haviam sido sujeitas. Para o território em estudo não possuímos dados que nos permitam confirmar estas suspeitas. No entanto, para a diocese de Viseu, sabemos que uma mulher, após ter sido condenada a dois anos de degredo e a pagar um marco de prata, em virtude da sua pobreza passou a viver numa casa do pároco da freguesia "que lhe faz esmola de a sustentar e alguma couza que tinha a tem vendido pera paguar ao meirinho e escrivão"84. Por outro lado, o cumprimento da pena de degredo tornaria a situação destas mulheres ainda mais frágil e vulnerável, especialmente aquelas que foram desterradas para as dioceses da Guarda e de Portalegre, já que o bispado de Leiria confinava com a freguesia de Pombal.

Relativamente à reforma dos comportamentos e à eficácia dos mecanismos de normalização social, as fontes esclarecem que nem todas as sentenciadas modificaram as suas condutas, inclusivamente aquelas que haviam sido sujeitas a processo no auditório eclesiástico. Refira-se a título de exemplo o caso de Luísa, solteira, da Roussa de Baixo, processada por aquela instância no seguimento das acusações de concubinato incestuoso com Manuel, seu parente em quarto grau de consanguinidade, registadas na devassa de 1692. O par, que havia solicitado dispensa para efectuar o matrimónio, voltaria a ser delatado em 1694 e em 1695, tendo sido novamente sujeito a livramento 85 .

A propósito da reforma das condutas, mencione-se ainda a resposta do pároco da Redinha, freguesia vizinha da de Pombal, a um inquérito remetido

84 Viseu, Arquivo Distrital de Viseu, Câmara Eclesiástica, Livro de Registo dos Sumários das Sentenças, 8/54, fols. 20-22, apud João Rocha Nunes, “Crime e Castigo [...]”, p. 211.

85 Coimbra, A.U.C., Devassas Penela, liv. 41, fols. 171v-172v e 180; liv, 45, fols. 90, 91, 93-93v e 96v; liv. 46, 236v e 238v-240. 
pelo prelado conimbricense na segunda metade do século XVIII. Segundo frei João dos Santos, vigário daquela paróquia "muitas mulheres vivem com muita dissolução e com escandalo desta mesma villa e se me faz precizo nomear algumas para que vossa senhoria the ponha o remedio, pois não tem bastado as muitas vizitas em que forão culpadas". Depois de declarar o nome de quatro mulheres e respetivos delitos, o pároco esclareceu o prelado que "todas estas forão ja denunciadas e sem reforma algũa e me pareçe a não terão, só exterminando-as”, isto é, sentenciando-as a degredo.

7. Como verificámos, a esmagadora maioria das delações registadas em sede de visita pastoral respeitou a delitos morais, dentro dos quais prevaleceram os casos de amancebamento. As acusadas eram sobretudo solteiras, de baixos estratos sociais, ainda que esporadicamente algumas escapassem a esse universo social típico.

Entre as distintas situações e estratégias individuais evidenciadas pelas fontes, ficou patente que determinados casos estiveram intimamente ligados à ideia de casamento, designadamente os casais que após os esponsais tinham relações sexuais e os que, tendo impedimento de parentesco, coabitavam, antes da necessária dispensa. Apesar de pretenderem casar, estes últimos incorriam em concubinato incestuoso, crime grave para o qual os textos normativos estipulavam penas assaz pesadas, pelo que a intenção, na maior parte das vezes, pouco lhes valia.

Ficou igualmente demonstrado que o disciplinamento social levado a cabo pelas autoridades eclesiásticas foi realizado, mormente sem ter lugar processo no juízo eclesiástico ${ }^{86}$. De facto, menos de $10 \%$ dos casos reportados em visita foi pronunciado a livramento, sendo a maioria das causas instauradas por relações incestuosas.

A análise das sentenças de dez mulheres, cujos autos correram no auditório no século XVIII, evidenciou que o estipulado nas constituições diocesanas, onde a condição específica da mulher surge evidenciada, nem sempre foi seguido à letra. A penalização mais gravosa passou pelo de-

86 O mesmo sucedeu na diocese de Viseu, cf. os trabalhos da autoria de João Rocha Nunes, já citados. 
gredo, decretado preferencialmente para as dioceses vizinhas da Guarda e de Leiria. Tratando-se essencialmente de gente humilde, o recurso para um tribunal superior foi bastante raro, pois carecia de meios para o fazer. No caso em apreço, localizámos apenas uma ré que conseguiu apelar para instância superior, tendo sido absolvida. Quanto ao cumprimento das penas, nem todas as sentenciadas satisfizeram a totalidade da condenação, pelo menos no imediato.

A eficácia dos mecanismos de disciplinamento social não foi, como dificilmente seria, total. As fontes esclarecem que várias mulheres persistiram nas suas condutas erróneas, mesmo depois de terem sido sujeitas a processo no auditório. Semelhantes casos motivaram inclusivamente um pároco a apresentar uma proposta radical ao prelado, entendendo que a única forma de cessar esses comportamentos era "exterminando-as".

Se como referimos o disciplinamento foi sobretudo feito por intermédio de exortações e de admoestações, como de resto preconizava o excerto com que abrimos este texto, tal deveu-se à política paciente de cristianização dos fiéis, adotada pela Igreja ${ }^{87}$. Era sobretudo essencial evitar a ruína espiritual, não só dos transgressores, mas igualmente do próximo que com escândalo haviam ofendido, o que era alcançado por intermédio do termo de admoestação. A estratégia requeria, pois, paciência e moderação. Mais do que punir era essencial catequizar.

87 A expressão é de José Pedro Paiva, Bruxaria e Superstição num País sem "caça às bruxas" 1600-1774, 2. ${ }^{a}$ edição, Lisboa, Editorial Notícias, 2002, pp. 352-354. 
Série Investigação

Imprensa da Universidade de Coimbra

Coimbra University Press

2015 